\title{
Heiner Syndrome: An uncommon cause of failure to thrive
}

\section{Ayotade B. Ojuawo ${ }^{1}$, Olutobi B. Ojuawo ${ }^{2}$, Adeniyi O. AladesanmI ${ }^{2}$, Mosunmoluwa O. Adio ${ }^{2}$, Mohammed B. Abdulkadir $^{1}$, Olugbenga A. Mokuolu ${ }^{1}$}

1. Department of Paediatrics and Child Health, University of Ilorin Teaching Hospital, Ilorin, Kwara State, Nigeria.

2. Department of Internal Medicine, University of Ilorin Teaching Hospital, Ilorin, Kwara State, Nigeria.
Date Received: 26-May-2018

Revision Received: 03-Dec-2018

Date Accepted: 31-Dec-2018

Correspondence: Olutobi. B. Ojuawo

(obk_ojuawo@yahoo.com)

\begin{abstract}
Heiner syndrome (HS) is a rare hypersensitivity reaction of an infant or young child to cow milk proteins. It is a disease characterised by failure to thrive, respiratory symptoms like cough, dyspnoea, wheeze and rhinitis with accompanying chest infiltrates on chest radiograph; gastrointestinal symptoms like vomiting, diarrhoea; and anaemia. The non-specific nature of the disease can result in delayed diagnosis and treatment and central to the condition is hypersensitivity to cow milk proteins.

Several cases have been reported worldwide but there has been no report of this condition in Africa.

We highlight the case of a sixteen week old child seen in our facility with features typical of Heiner syndrome. Clinicians should have a high index of suspicion for this condition especially in children predominantly on infant formula.
\end{abstract}

Keywords: Heiner syndrome, Cow milk proteins, Hypersensitivity, Failure to thrive, Infant formula

\section{Introduction}

Heiner syndrome (HS), also known as cow milk induced pulmonary disease is a rare disease resulting in atypical lung disease in infants and young children ${ }^{1}$. It is characterised by recurrent respiratory tract symptoms, infiltrates mimicking pneumonia on chest radiograph, fever, anaemia and failure to thrive. Some patients with the condition have also been reported to have gastrointestinal symptoms such as anorexia, vomiting, diarrhoea, abdominal pain and bloody stools $^{1,2}$. These clinical features are however noticed to resolve within one to three weeks of discontinuation of cow milk ${ }^{1,2}$. The varied nature of the disease usually results in delayed diagnosis and treatment but the presence of precipitating antibodies against cow milk proteins further helps to strengthen diagnosis of the disease ${ }^{2}$.

The disease was first reported by Heiner et $\mathrm{al}^{3}$ in the United States of America (USA) in a group of seven children who were 6 weeks to 17 months old on cow's milk who had recurrent respiratory symptoms and infiltrates on chest radiograph. Another review of eight cases by Moissidis et $\mathrm{al}^{2}$ in the USA revealed that most children with the disease were diagnosed between the $4^{\text {th }}$ and $29^{\text {th }}$ month of life. A few other case reports have been reported on the disease in the USA $^{1,4,5}$, Italy ${ }^{6}$ and Turkey ${ }^{7}$ However, there is no report from Africa. We report a case of a sixteen week old infant with the condition seen in our facility.

\section{Case Presentation}

A sixteen week old male infant who was a product of term gestation presented with poor weight gain and respiratory distress noticed at $10^{\text {th }}$ week of life. He was delivered to a primiparous woman at gestational age of 40 weeks and 4 days via assisted delivery (vacuum delivery). His mother had no fever or rash all through the antenatal period. Apgar scores were 8 and 10 in the first and fifth minutes respectively. His birth weight was $2.8 \mathrm{~kg}\left(12^{\text {th }}\right.$ percentile $)$ with a head circumference of $34 \mathrm{~cm}\left(36^{\text {th }}\right.$ percentile) and length of $50 \mathrm{~cm}\left(52^{\text {nd }}\right.$ percentile). Poor weight gain was noticed about 4 weeks after birth. Child was exclusively breastfed in the first week of life but subsequently commenced on infant formula in the second week of life as mother was not lactating adequately. He was receiving $150 \mathrm{mls} / \mathrm{kg} /$ day of infant formula ( 67 calories $/ 100 \mathrm{mls}$ ) as well as breast milk. No history of passage of frequent loose stools, no passage of pale coloured stools, no vomiting, no abdominal distension. He occasionally had hard stools.

He had no signs of jaundice and no rash. Respiratory distress was noticed also around the $10^{\text {th }}$ week of life evidenced by tachypnoea. Respiratory rate had ranged between 60 and 70 breaths/minute as observed by his mother who is a medical practitioner. There was associated cough and nasal discharge. No wheeze and no ear discharge. He had no significant improvement despite a seven day antibiotic therapy with amoxicillin/clavulanic acid and cefuroxime at doses of $15 \mathrm{mg} / \mathrm{kg}$ twice daily which had been prescribed by a general practitioner on separate occasions based on suspicion of pneumonia. His weights from his immunization charts which were up to date were found to have been $2.9 \mathrm{~kg}$ at 6 weeks ( $<3^{\text {rd }}$ percentile), $2.78 \mathrm{~kg}$ at 10 weeks $\left(<3^{\text {rd }}\right.$ percentile) and $3 \mathrm{~kg}$ at 14 weeks $\left(<3^{\text {rd }}\right.$ percentile). On arrival to the emergency department in the sixteenth week of life, he was febrile with an axillary temperature of $37.8^{\circ} \mathrm{C}$. His weight was $3.25 \mathrm{~kg}\left(<3^{\text {rd }}\right.$ percentile). Physical examination revealed clinical pallor, tachypnoea of 60 breaths per minute with nasal flaring and subcostal recessions. However, there was no head nodding, grunting or wheezing. The trachea was central with the apex beat at the $4^{\text {th }}$ left intercostal space along the midclavicular line. Auscultation of the lung fields revealed few crepitations in the right middle and lower lung zones. 
Abdominal examination revealed hepatosplenomegaly. The liver was palpable $6 \mathrm{~cm}$ below the right costal margin with a liver span of $10 \mathrm{~cm}$, firm, non-tender with no hepatic bruit. The spleen was palpable $2 \mathrm{~cm}$ below the left costal margin.

Laboratory studies revealed profound microcytic anaemia [haemoglobin $7.0 \mathrm{~g} / \mathrm{dL}(11.5-14 \mathrm{~g} / \mathrm{dL})$, mean corpuscular volume of 52 femtolitres (74-108fL) and mean corpuscular haemoglobin 26 picograms (27-35pg)], total white blood cell count of $13.1 \times 10^{9} / \mathrm{L}\left(4.0-10 \times 10^{9} / \mathrm{L}\right)$ (neutrophils - 40\%, lymphocytes - 53\%) and a platelet count of $407 \times 10^{9} / \mathrm{L}$ $\left(250-400 \times 10^{9} / \mathrm{L}\right)$. Haemoglobin assessment using high performance liquid chromatography revealed Haemoglobin A - 65.1\%, Haemoglobin A2 - 3.7\% (1.7-3.3), Haemoglobin F - 5.2\% (3.5-9.5\%) and Haemoglobin S - 26\% (3.5-9.5); indicating a haemoglobin genotype of AS. Multiple serum bicarbonate levels were consistently between $16-22 \mathrm{mmol} / \mathrm{L}$ $(22-28 \mathrm{mmol} / \mathrm{L})$ though other serum electrolytes, urea and creatinine were within normal reference limits. Urinalysis revealed a urine $\mathrm{pH}$ of 6 and 6.5 on several occasions with other parameters being normal. Liver and thyroid function tests were also within normal limits. HIV screening done to ascertain exposure was negative. His blood film for malaria parasite was negative for Plasmodium species and automated blood culture with $\mathrm{BacT} / \mathrm{Alert}{ }^{\circledR}$ did not isolate any organism. His plain chest radiograph showed patchy opacities in the upper and middle lung zones bilaterally though worse on the left hemithorax (Figure 1). Abdominopelvic ultrasound confirmed hepatosplenomegaly. The liver span was $9 \mathrm{~cm}$ while the splenic length was $6 \mathrm{~cm}$ Echocardiography was normal asides for mild pericardial effusion $(0.2 \mathrm{~cm}$ maximum diameter) and increased flow velocity across the pulmonary valve. Transfontanelle ultrasonography was unremarkable.

The initial working diagnosis was failure to thrive from suspected renal tubular acidosis and he was commenced on oral sodium citrate with little or no clinical improvement after 2 weeks. Also, iron supplements were given for about a month without substantial improvement on his haematological parameters. He however began to make significant improvement with introduction of soy based diet at the $5^{\text {th }}$ month of life and weight gain improved remarkably with guinea corn/millet (porridge) and soybeans based (infant formula) diet. The recurrent respiratory symptoms were also noticed to have resolved 2 weeks after introduction of the new diet. This led to a diagnosis of cow milk hypersensitivity based on the constellation of clinical features and subsequent resolution after stopping cow milk. However, facilities for immunoglobulin $G$ assays to cow milk proteins were not available to further strengthen the diagnosis. His weight at nine months was $7.8 \mathrm{~kg}\left(11^{\text {th }}\right.$ percentile $)$ and follow up check at one year revealed a weight of $8.9 \mathrm{~kg}$ ( $23^{\text {rd }}$ percentile). At 12 months of age, his haematological and biochemical parameters were all within normal reference ranges. Serum bicarbonate level was $24 \mathrm{mmol} / \mathrm{L}(22-28 \mathrm{mmol} / \mathrm{L})$. However, his parents on a follow up outpatient visit affirmed to occasional cough and rhinitis whenever milk based diet was reintroduced and they were appropriately counselled on avoidance. His body weight at 18 and 24 months following strict dietary adherence was $10.9 \mathrm{~kg}\left(49^{\text {th }}\right.$ percentile) and $11.8 \mathrm{~kg}\left(40^{\text {th }}\right.$ percentile) respectively. His growth chart from birth to the end of the $2^{\text {nd }}$ year of year is illustrated in Figure 2.

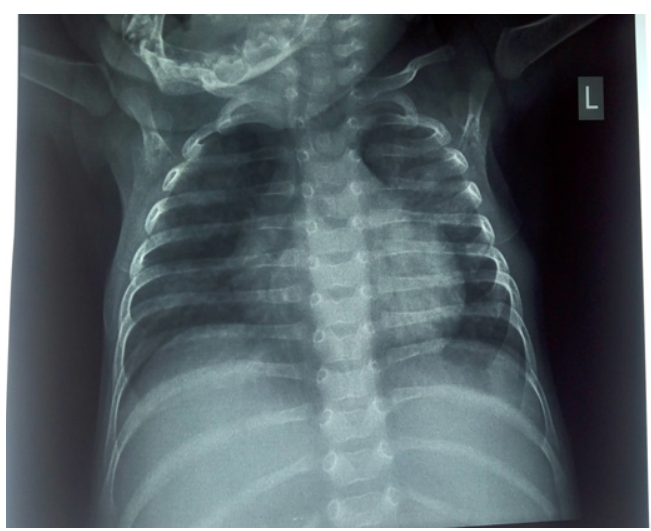

Figure 1: Plain chest radiograph revealing infiltrates in the upper and middle lung zones bilaterally

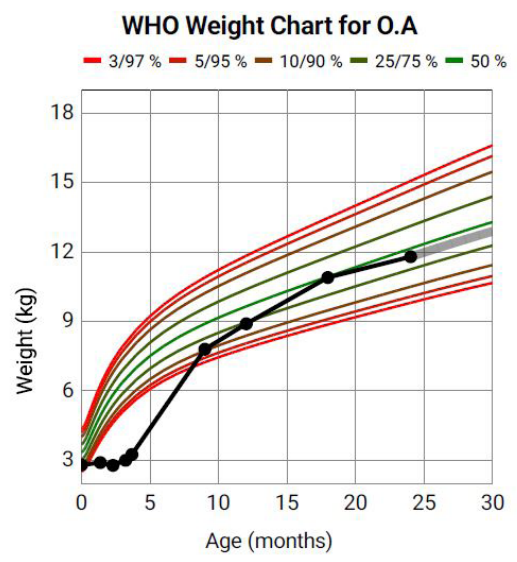

Figure 2: WHO growth chart of the child from birth to 24 months of age.

\section{Discussion}

HS is a rare hypersensitivity pulmonary disease ${ }^{2}$ and the precise mechanism responsible for this syndrome is still poorly understood. However, it is assumed to occur as a result of type 3 hypersensitivity reaction/immune complex depositions. A cell mediated reaction has also been suggested to contribute to the development of the disease ${ }^{8}$. The disease came to the fore when Heiner and his colleagues reported in 1962, the presence of circulating antibodies to cow milk antigens in infants who had presented with cough, infiltrates on chest radiograph, poor weight gain, gastrointestinal symptoms and anaemia ${ }^{3}$. The symptoms of the disease usually commence before the age of one and may occur up to the fifth year of life ${ }^{4}$. Furthermore, Moissidis et $\mathrm{al}^{2}$ in their case series also reported a range of 1-9 months as the period of onset of symptoms following introduction of cow's milk. An estimated 10\% of children with the disease manifest with the severe form of the disease which could culminate in pulmonary haemosiderosis. ${ }^{4}$ HS is basically a clinical diagnosis and features of this disorder include recurrent upper or lower respiratory tract symptoms such as cough, dyspnoea, wheeze or rhinitis; gastrointestinal symptoms such as vomiting or diarrhoea; failure to thrive, fever, patchy infiltrates on chest radiograph and iron deficiency anaemia ${ }^{2}$. Hepatomegaly, splenomegaly and peripheral lymphadenopathy may be present in rare occasions ${ }^{5}$. Our highlighted case had virtually all the symptoms above except the wheeze and his gastrointestinal symptom was constipation. Iron-laden macrophages on bronchial or gastric aspirates may be detected in some cases as well as the presence of precipitating $\operatorname{IgG}$ antibodies to cow's milk ${ }^{2}$. Strongly positive levels of serum precipitating https://dx.doi.org/10.4314/mmj.v31i3.11 
IgG antibodies to nine cow's milk protein fractions was reported by Sigua et $\mathrm{al}^{1}$ as well as slightly elevated $\operatorname{IgM}$ and negative serum specific IgE to cow's milk. However, serum specific $\operatorname{IgE}$ antibodies may also be found in some children ${ }^{3}$. Elevated levels of anti-nuclear antibodies (ANA) has also been reported in a case report ${ }^{1}$. The diagnosis of HS is strongly supported by the resolution of the aforementioned clinical features following strict avoidance of cow milk ingestion ${ }^{1}$ which was demonstrated by our patient. Many subjects tend to recover within 5-21 days of removal of cow milk from their diet and reoccurrence of symptoms has been reported with reintroduction ${ }^{2,5}$. It is however believed that some children may be able to eventually tolerate cow milk within a few years and this can be tested by reintroducing denatured or heated cow milk first whilst strongly watching out for the symptoms. The complications from the disease contribute significantly to morbidity and mortality and occur in settings of delayed diagnosis and treatment. These include alveolar hypoventilation, massive acute pulmonary haemosiderosis, pulmonary hypertension and cor pulmonale ${ }^{5,10}$. Crescentic glomerulonephritis was also reported as a complication by Yavuz et $\mathrm{al}^{7}$ in Turkey; further demonstrating the multisystemic involvement of the disease.

\section{Conclusion}

HS is a cause of failure to thrive, respiratory and gastrointestinal symptoms as well as anaemia. It can mimic so many diseases thus contributing to it's under diagnosis, delayed treatment and increased medical costs. HS should be considered in any infant on infant formula who presents with poor growth, anaemia and unexplained chest symptoms of at least one month duration which does not resolve with antibiotic therapy. This will mitigate against the possible deleterious consequences that can occur as a result of the disease.

\section{References}

1. Sigua JA, Zacharisen M. Heiner syndrome mimicking an immune deficiency. WMJ 2013;112(5):215-217. PMID: 24734417.

2.Moissidis I, Chaidaroon D, Vichyanond P, Bahna SL. Milk-induced pulmonary disease in infants (Heiner syndrome). Pediatr Allergy Immunol 2005;16(6):545-552. doi: 10.1111/j.1399-3038.2005.00291.x

3.Heiner D, Sears J, Kniker W. Multiple precipitins to cow's milk in chronic respiratory disease: a syndrome including poor growth, gastrointestinal symptoms, evidence of allergy, iron deficiency anemia, and pulmonary hemosiderosis. Am J Dis Child. 1962;103(5):634-654. doi: 10.1001/archpedi.1962.02080020649003.

4.Lee SK, Kniker W, Cook C, Heiner D. Cow's milk-induced pulmonary disease in children. Adv Paediatr. 1978;25:39. PMID: 742552.

5.Boat TF, Polmar SH, Whitman V, Kleinerman JI, Stern RC, Doershuk CF. Hyperreactivity to cow milk in young children with pulmonary hemosiderosis and cor pulmonale secondary to nasopharyngeal obstruction. J Paediatr. 1975;87(1):23-29. doi: 10.1016/s00223476(75)80062-x

6.Fossati G, Perri M, Careddu G, Mirra N, Carnelli V. [Pulmonary hemosiderosis induced by cow's milk proteins: a discussion of a clinical case. Pediatr Med Chir.1992;14(2):203-207. PMID: 1508757.

7.Yavuz S, Karabay-Bayazit A, Yilmaz M, Gonlusen G, Anarat A. Crescentic glomerulonephritis in a child with Heiner syndrome. Turkish J Pediatr. 2014;56(6):661-664.

8.Stafford HA, Polmar SH, Boat TF. Immunologic studies in cow's milk-induced pulmonary hemosiderosis. Pediatr Res. 1977;11(8):898903. doi: 10.1203/00006450-197708000-00009

9.Holland NH, Hong R, Davis NC, West CD. Significance of precipitating antibodies to milk proteins in the serum of infants and children. J Paediatr. 1962;61(2):181-195. doi: 10.1016/s00223476(62)80252-2

10. Williams S, Craver R. Cow's milk-induced pulmonary hemosiderosis. J La State Med Soc. 1989;141(8):19-22. PMID: 2769010 